\title{
EM BUSCA DO PERFEITO REALISMO
}

Manuela Penafria ${ }^{1}$

"I see the cinematographic art as two currents, actualities, on the one side, on the side fiction [sic], in the middle, documentary swims, is sometimes very linked to fiction film, but sometimes very near actualities." Joris Ivens ${ }^{2}$

\section{INTRODUÇÃO}

O Cinema tem sido essencialmente estudado a partir do filme de longametragem de ficção. Esta é a face mais visível da produção, distribuição e exibição cinematográfica. $\mathrm{O}$ que nos propomos é contribuir para inverter esta ordem e tentarmos pensar o Cinema a partir do filme documentário. Entendemos que esta inversão contribui para balizar o estudo do documentário. Conscientes do risco iminente de cair em generalizações forçadas, temos como certo de que o que está aqui em causa são as questões que se colocam ao filme documentário constituem um modo legítimo de pensar o Cinema. A isto podemos acrescentar uma outra razão: há ainda um longo caminho a percorrer no estudo e, sobretudo, na clarificação de conceitos referentes ao filme documentário.

1 Doutoranda em cinema pela Universidade de Beira Interior, Covilhã, Portugal; Dept. de Comunicação e Artes. [manuela.penafria@gmail.com]

2 Citado em Bill Nichols, "The documentary and the turn from Modernism" in Kees Bakker (ed.) Joris Iens and the documentary context, Amsterdam University Press, 1999. 
Em vez de tentarmos responder à questão: "O que é o filme documentário?" 3 interessam-nos as questões: "Como pensar o filme documentário?"; “Que lugar ocupa no Cinema?”. O "documentarismo", termo que já utilizámos em vários textos foi considerado uma teoria ou disciplina, um modo de ver o cinema, através das questões que se colocam ao documentário. É nesse sentido que o presente texto se enquadra e, em grande parte, coloca à prova e testa essa abordagem.

O realismo das imagens não é uma questão que se coloca apenas ao filme documentário. As teorias realistas do cinema de André Bazin (19181958) e Siegfried Kracauer (1889-1966) são uma referência para todos os que se interessam por cinema. Em grande parte, essas teorias deixam de lado o filme documentário ${ }^{4}$ mas, se é inegável que a questão do realismo entusiasma discussões, há uma outra questão que se coloca ao documentário com a mesma pertinência, a saber, a Ética. Esta é uma dimensão que se coloca logo no momento em que se pretende fazer um filme uma vez que está em causa, na grande maioria dos casos, a representação do Outro. Em suma, o que pretendemos é ir buscar ao filme documentário a questão da Ética para ver de que modo ela se relaciona com a do Realismo.

Mas, para começar, iremos tentar esclarecer a nossa posição face à problemática ficção-documentário.

\section{PROBLEMATIZAR}

$\mathrm{Na}$ discussão sobre as diferenças entre documentário e ficção, não nos interessa encontrar as diferenças, interessa-nos mais o que os

3 Questão que nos ocupou em $O$ Filme Documentário. História, identidade, tecnologia. Ed. Cosmos,Lisboa, 1999 e no artigo "O filme documentário em debate: John Grierson e o movimento documentarista britânico” (2004, VI LUSOCOM, UBI) defendemos que definir o documentário é pensá-lo enquanto género.

4 Há razões para que Bazin e Kracauer se tenham apenas referido ao documentário sem nunca the atribuirem lugar de destaque nas suas teorias. Poderão existir outras, mas se tivermos em conta as datas em que ambos autores formularam o seu pensamento, não é difícil verificar que a grande produção de documentários esbarra com a propaganda. São filmes que analisam acontecimentos, ora Bazin opõe-se à planificação, à decomposição de um acontecimento em vários planos, pois isso é ir no sentido contrário ao cinema realista que se apoia, em grande parte, no plano-sequência. Já em Kracauer, há que ter em conta que um dos seus principais pontos de partida é precisamente a crítica às ideologias pois estas impedem que o Homem estabeleça uma relação próxima com o mundo físico. 
une que aquilo que os separa. Podemos avançar com a proposta seguinte: documentário e ficção são cinema e, por isso, consideramos que um e outro têm a mesma natureza, entre eles apenas existe uma diferença de grau. Há filmes que não oferecem dúvidas quanto ao género a que pertencem, mas há um grande número que se situa na fronteira. Diz-nos Deleuze que antes do Neo-realismo italiano predomina o regime da imagem-movimento e, acrescentamos, os filmes não oferecem resistência a uma classificação rígida como seja a de ficção ou documentário. Com e após o Neo-realismo italiano - diz-nos Deleuze que passa a predominar o regime da imagemtempo - é cada vez mais difícil (e, em alguns casos, impossível) classificar os filmes. ${ }^{5}$ Cada vez mais os filmes são menos ficção ou documentário, são filmes de fronteira. E são esses filmes que nos fazem julgar correcta a nossa proposta. Essa proposta pretende colocar ficção e documentário lado a lado, por partilharem um uso de imagens e sons, ambos são cinema. Pelo menos até à presente data, nada nos parece suficientemente convincente para considerarmos o filme documentário o legítimo representante da realidade. Ou seja, não concordamos em legitimar o filme documentário, isso seria relegar a componente documental que se encontra na ficção, que não é tão pouca quanto isso.

Sempre nos referimos ao documentário cinematográfico, deixando de lado outras manifestações como o documentário televisivo, a reportagem, a fotografia ou o reality show por considerarmos estas representações dentro de uma categoria maior designada por não-ficção. Já em outro momento considerámos que o documentário faz parte desta categoria. ${ }^{6}$

A tendência actual de baralhar fronteiras, de colocar uma cada vez maior confusão entre documentário e ficção abala o estatuto privilegiado dos documentários. ${ }^{7} \mathrm{O}$ "mock-documentary" de que é exemplo The Blair Wicht project (1999), de Daniel Myrick e Eduardo Sánchez são filmes de

5 Isto não quer dizer que antes do Neo-realismo italiano os filmes apenas são documentário ou ficção (podemos considerar os filmes de Eisenstein como documentários, por exemplo) mas, o que está aqui em causa é que depois desse movimento a interferência entre géneros é mais evidente.

6 Penafria, O Filme Documentário. História, Identidade, Tecnologia. Edições Cosmos, Lisboa, 1999.

7 O livro Faking it, Mock-Documentary and the Subversion of Factuality de Jane Roscoe e Craig Hight, Manchester University Press, 2001, é uma reflexão sobre esse tipo de filmes. 
ficção que colocam o espectador na dúvida sobre se, de facto, o que vemos aconteceu mesmo, no caso, a câmara ao ombro enquanto recurso recorrente, estimula essa dúvida. Se, por hipótese, este filme fosse classificado e exibido a uma comunidade de espectadores que não tenha tido acesso a outras informações sobre o filme, seria demasiado fácil defender a sua forte presença indicial. Aqui o conceito de "indexação" de Noël Carroll (1996) é importante. "Indexar" um filme de ficção ou documentário ou com outra designação, parte do realizador sendo posteriormente reconhecida pela comunidade; por exemplo, mesmo que Star Wars fosse "indexado" de nãoficção, isso seria recebido com severas críticas. A “indexação” é sem dúvida um conceito importante; mas seria mais útil considerá-la sempre como algo provisório. Nada nos garante que as nossas "indexações" não sejam reindexadas ainda que num futuro longínquo e com isso fiquem baralhadas as duas certezas da "indexação": diz-nos a que mundo o filme alega referir-se e diz-nos o tipo de resposta e expectativas que é legítimo termos perante um filme ${ }^{8}$. Que razões há para classificar $J F K(1991)$ de Oliver Stone, de "ficção" ou "ficção documentada". Porque não indexá-lo de "documentário ficcionado"? Aqui, parece-nos que é tão legítimo evidenciar a componente ficcionada como a componente documental.

Se o conceito de indexação não nos satisfaz, então há que procurar uma alternativa. Podem os filmes não ser verdadeiros (como sabemos, espera-se que o filme documentário estabeleça entre o filme e o que the é exterior uma relação de verdade), mas há uma verdade que cada filme constrói. E isto é acreditar no cinema e não apenas neste ou naquele género.

A questão é que as objectivas das câmaras, ao contrário do que o seu nome indica, não são objectivas. Há um “compromisso genealógico que liga a concepção tecnológica da câmara e das lentes cinematográficas (que metonimizam a globalidade do dispositivo) aos códigos figurativos da representação em perspectiva linear, tais como surgem definidos e codificados pelos tratados de pintura e arquitectura do Renascimento." (João

8 "tells us what the film claims to refer to, i.e., the actual world or segments of possible worlds" e "the kind of responses and expectations it is legitimate for us to bring to the film". (Carroll, 1996:238). 
Mário Grilo, 1997:255) “o que importa assinalar é o facto da produção de efeito de realidade do cinema não advir da realidade, mas dos códigos utilizados para a sua representação.” (João Mário Grilo, 2000:14).

Os próprios cineastas não depositam confiança na objectividade do dispositivo, nas câmaras de filmar. Frederick Wiseman conhecido e referenciado como cineasta de "documentários de observação" diz: "tento captar todos os aspectos da vida do local onde filmo, e o filme final é uma reflexão sobre esta complexidade da vida que vemos nestes sítios. (...) É mais interessante para mim descobrir o que penso sobre o assunto que filmei. Não será obrigatoriamente mais interessante do que qualquer outra pessoa poderá pensar, mas eu não me posso pôr na cabeça dessa outra pessoa! Quando faço um filme descubro o que penso." (Wiseman, 1994:41-42). A confiança na tecnologia coloca em suspenso a magistral fórmula magritiana "Ceci n'est pas un pipe" e deixa de lado uma importante dimensão da realização fílmica, que os filmes não são "feitos sobre...", mas "feitos com...", como diria Nicholas Philibert ou, como já tinhamos proposto, "a realidade a que um filme nos dá acesso é menos a realidade em si e mais o relacionamento que o autor do filme tem com os intervenientes do filme". ${ }^{9}$

Porventura apenas os realizadores do "cinema directo" num primeiro momento, entusiasmados com o equipamento portátil de som síncrono, tenham proclamado uma aproximação à realidade mas, a possibilidade de fazerem filmes muito diferentes dos seus antecessores é um aspecto importante para esses realizadores. Novamente Wiseman: "Os que foram pioneiros dessa técnica, como Leacock ou Pennebaker, mostraram-me o que se poderia fazer com equipamento portátil leve. Do ponto de vista tecnológico, o que eu faço é a mesma coisa. Onde sou diferente é na escolha de assuntos e na montagem. E suponho que o que eu fazia era em parte uma reacção contra algum documentário anterior, e contra o estilo desse documentário, na medida em que era um documentário sobre gente famosa - políticos, estrelas de cinema, criminosos...- e que o que me interessava a mim era fazer filmes em que a estrela era o lugar e onde teria um cast

9 Penafria, "O ponto de vista no filme documentário" (2001). www.bocc.ubi.pt 
muito mais alargado. Queria ter a oportunidade de olhar para uma gama de comportamentos mais vasta." (Wiseman, 2004:60).

Todo o filme é documental porque remete para pontos de vista, para modos de pensar, para modos de ver o mundo. Documentário e ficção são dois modos de documentar, de comentar o mundo. Retirar a componental documental dos filmes de ficção é retirar-lhes uma componente essencial mas, também, podemos dizer que retirar ao documentário a sua parte ficcional é retirar-lhe uma componente essencial. Não havendo uma fronteira nítida, colocamo-nos nessa zona de fronteira para dizer que da nossa parte o que nos interessa é a verdade cinematográfica. E esta é a nossa alternativa ao conceito de "indexação".

Denize Correa Araujo (2004) numa reflexão sobre as tendências contemporâneas da cinematografia brasileira realça os filmes que constituem "linhas de fuga" em oposição a outros que "reforçam os estereótipos da violência, pobreza e subdesenvolvimento” como, por exemplo, Cidade de Deus (2002) de Fernando Meirelles. Nesse artigo, os filmes analisados enquanto "linhas de fuga" e que enfatizam "o outro lado, que é também parte dos tantos brasis que coexistem no imenso cenário do país” são: Janela da alma (2001) de João Jardim e Walter Carvalho, um documentário e Durval Discos (2002) de Anna Muylaert, uma ficção. Araujo afirma: "A escolha destes dois filmes reflete minha intenção de enfatizar que, tanto no gênero documentário quanto na narrativa de ficção, a cinematografia brasileira tem sido presenteada com raros momentos de sensibilidade e transcendência que, embora não valorizada por muitos, não deixam de ser de extrema relevância." Ambos "escolhendo elementos estéticos e questionamentos filosóficos para transcender o cotidiano violento, a mimética transcrição da violência e a espetacularização do horror." Ou seja, a pertença a um determinado género não é relevante. É precisamente este tipo de análise que nos interessa ou, como já referimos, o que une documentário e ficção.

Lado a lado: documentário e ficção. Se toda a imagem é falsa, o mesmo princípio aplica-se a ambos, se toda a imagem é verdadeira, o mesmo princípio aplica-se a ambos. Se toda a imagem é ao mesmo tempo falsa e verdadeira, o mesmo princípio aplica-se a ambos. Não entendemos haver razão nenhuma que confira uma maior legitimidade ao filme documentário. 
Brian Winston, em entrevista ao canal português de televisão RTP 2, no programa Odisseia das Imagens - que mostrou filmes do Ciclo Olhar de Ulisses, Porto, Capital Europeia da Cultura 2001 - diz que o que há de errado no filme $O$ Triunfo da Vontade (1935) de Leni Riefenstahl não é o facto de ser um filme de propaganda, mas sim o seu conteúdo. $\mathrm{O}$ que Winston contesta é a alegada objectividade ou falta de ponto de vista nos documentários. Sendo impossível não ocupar um lugar, não falar de um determinado ponto de vista, há que assumir essa condição. Em suma, interferir, manipular é viver. O que deverá estar sempre em causa são os pontos de vista. E os documentários são isso mesmo, pontos de vista.

\section{RELACIONAR: REALISMO, UMA QUESTÃO DE ÉTICA?}

Os documentaristas são, muitas vezes, confrontados com situações capazes de colocarem à prova as normas morais que possam ter como certas. Uma plataforma de entendimento com os intervenientes do filme é essencial, estes são a primeira prova de teste às qualidades do documentarista. Não será demasiado afirmar que em mais nenhum outro filme as questões éticas assumem tanta importância. ${ }^{10}$

A responsabilidade do documentarista para com as pessoas que filma e para com o espectador são os dois pólos das questões éticas. Seguimos aqui Brian Winston (2000) que defende que as questões éticas referentes à relação documentarista-intervenientes no filme ("social actors") são mais importantes que o direito do público em ser informado. Assim, iremos tentar discutir esta questão a partir de um enquadramento mais abrangente - recorrendo à disciplina de Ética.

${ }^{10}$ Embora não abundem, há algumas referências a ter em conta no que diz respeito à discussão de questões éticas no filme documentário. O capítulo "Why are ethical issues central to documentary filmmaking?” de Bill Nichols no seu livro Introduction to Documentary (2001); Brian Winston, Lies, Damn Lies and Documentaries, BFI Publishing, 2000 e, do mesmo autor, os artigos: " 'Honest, straightforward re-enactment': the staging of reality" in Kees Baker (ed.) Joris Ivens and the Documentary Context, Amsterdam University Press, 1999 e "The tradition of the victim in griersonian documentary" in Alan Rosenthal, New Challenges for Documentary, University of California Press, 1988. Neste livro, o artigo de Winston faz parte do capítulo "Documentary ethics" onde constam outros artigos que discutem várias questões: 0 direito de informar vs direito à privacidade, questões que se colocam ao realizador que filma a sua própria família, entre outras. 
Antes de mais, é necessário distinguir Ética de Moral. "O termo grego ethiké apresenta uma dupla etimologia já anotada por Aristóteles, o qual o relaciona com éthos, escrito com a vogal longa eta, que tem o sentido de carácter, e com êthos, escrito com a vogal breve epsilon, que tem o sentido de hábito ou costume." (José Manuel Santos). Assim, enquanto disciplina, a Ética tem um duplo objecto, os "costumes" e o "carácter". Por um lado, temos uma "vertente social" que "tematiza um determinado tipo de costumes, cujas normas são interiorizadas por socialização e colectivamente aceites numa dada sociedade.” E, por outro lado, uma vertente psicológica, "relativa à aquisição e desenvolvimento da consciência ética no indivíduo." Ainda seguindo José Manuel Santos: "Os latinos optaram pelo termo mores, que significa costumes, para traduzir os termos gregos relativos à ética, tendo assim, surgido o termo 'moral'." Ética e moral são muitas vezes usados indistintamente mas, no "discurso ético estes termos adquirem significados mais precisos. "Ética" é muitas vezes utilizado para designar a disciplina ou a ciência que tematiza as normas morais, e, no caso dos éticos da corrente kantiana, as "fundamenta". "Moral" designa as normas morais que um grupo humano se dá espontâneamente a si próprio, sejam elas objecto de teorização ou não."11

O que aqui nos propomos fazer é verificar de que modo a Ética pode contribuir para a problemática do realismo no cinema.

A ligação cinema-realismo possui dois aspectos-chave: percepção e representação. (Cf. Dudley Andrew, 1984:63). O que, grosso modo, quer dizer que de entre todos os modos de representação, o cinema é o mais realista pela sua capacidade de restituir a ambiência visual e sonora de uma aç̧ão, objecto, lugar...

Nessa sua capacidade, o que está em discussão é o realismo e a ilusão da imagem cinematográfica. Por um lado, o todo ou parte do dispositivo cinematográfico tem a capacidade de reproduzir o que tem existência fora das imagens lançando uma extrema "impressão de realidade", considera-

${ }^{11}$ No feminino, o termo moral refere-se à "parte da Filosofia que trata das condutas e das práticas do homem em relação com a ideia de bem.” (in Os termos Filosóficos, Publicações Europa-América, 1989) Então, usado no masculino, por exemplo: "A Rita está com um moral péssimo", refere-se apenas ao estado de desalento do seu estado de espírito e não que a Rita tenha uma má conduta para com o Outro. 
se então que a natureza da imagem é a re-presentação de algo; por outro lado, essa impressão deriva de um trabalho de camuflagem do processo de produção a favor de uma naturalidade aparente, por isso considera-se que o realismo é o resultado de um conjunto de convenções e não de uma suposta "transparência".

No livro Teorías del Cine (1994), uma análise das teorias cinematográficas de 1945 a 1990, Francesco Casetti divide essas teorias em três paradigmas que caracterizam a forma de trabalhar de outras tanta gerações, a saber, teorias ontológicas, teorias metodológicas e teorias de campo. As teorias realistas encontram-se nas primeiras pois têm por objecto a essência do cinema. Bazin e Kracauer defendem que essa essência é a qualidade/capacidade fotográfica do cinema.

Segundo Casetti, a II Guerra não representa uma ruptura nas teorias cinematográficas, no entanto, algumas tendências afirmam-se com mais vigor após 1945, como seja a "valorização da dimensão realista". Embora o debate sobre a relação cinema-realidade seja anterior à II Guerra - faz parte do início história do cinema -, Casetti entende que só no pósguerra passará de "pretensão marginal a hipótese sólida". "Entre outras coisas, porque já não se baseia em razões de estilo ou em motivos de eficácia, mas numa necessidade intrínseca. Com efeito, a ideia é que o cinema deve orientar-se para o real por causa da sua "base fotográfica" , que lhe permite converter-se em testemunho e documento, pois está construído para registar o que se encontra frente à câmara." (Casetti, 1994:31/32 - nossa tradução e sublinhado)

Ainda segundo Casetti, esta proposta teórica comporta uma mudança radical. Se o cinema enquanto mero meio reprodutor não podia aceder ao estatuto de arte, é no pós-guerra que "a dimensão reprodutora do cinema se converte na sua força”. As teorias de Bazin e Kracauer vão precisamente consolidar essa força, afirmando a vocação realista do cinema. ${ }^{12}$

${ }^{12}$ Algumas referências sobre Bazin e Kracauer: J. Dudley ANDREW, The Major Film Theories: an Introduction, Oxford University Press, 1976; do mesmo autor, o artigo "André Bazin's 'Evolution'” in Peter Lehman (ed.) Defining Cinema, The Athlone Press, 1997 pp.73-94. Francesco Casetti, Teorias del Cine, Catedra, 1993; Robert Lapsley e Michael Westlake, Film Theory: an Introduction, Manchester University Press, 1988 e o artigo de Noël Carroll, "Kracauer's Theory of film" in Peter Lehman, Defining Cinema, Athlone Press, 1997, pp. 111-131. 
O texto "Ontologia da imagem fotográfica" de Bazin considerado um texto fundamental da sua teoria realista e que inicia o volume $O$ que é o Cinema? ${ }^{13}$ é, para Dudley Andrew (1997), um estranho fundamento para qualquer teoria de cinema uma vez que se trata de um ensaio sobre a fotografia. Aparentemente, considera Andrew, para compreendermos o que é o cinema não é tanto necessário compreendermos o que é a ontologia, mas a psicologia que está por detrás da função social e experiência pessoal das imagens visuais, por isso, Andrew defende que em Bazin o realismo não é tanto uma categoria estética, mas mais um impulso, um objectivo, uma função. Ainda que assim seja, o que nos parece aqui relevante é colocar em causa que o pensamento de Bazin seja de facto ontológico.

A este respeito recorremos ao artigo de António Fidalgo (no prelo) onde o autor afirma que: "os objectos do cinema não são os objectos físicos, mas os novos objectos superiores ou de segunda ordem (no vocabulário da objectologia de Meinong), das relações (...) Sentimentos, paixões, ideias, atracção, repulsa, medo, intriga, distância, proximidade, tudo isso são relações, os objectos próprios do cinema." ${ }^{14} \mathrm{~A}$ ser assim, e seguimos esta proposta, o que está aqui em causa é que a qualidade fotográfica do cinema em que as teorias realistas se apoiam, só pode, no melhor dos cenários, ser entendida como apenas uma das características da imagem. Ou seja, essa qualidade não serve como fundamento para uma teoria ontológica.

Um ponto fundamental é o facto das teorias realistas serem datadas do pós-guerra. Esta observação, que como vimos atrás, é enfatizada por Casetti, leva-nos a crer que, nas teorias realistas, não está tanto em causa o que o cinema é, mas o que o cinema deve ser. Em suma, se as teorias realistas dizem respeito ao que o cinema deve ser, então essas teorias não podem ser ontológicas, uma vez que constroem o seu edifício numa base pouco sólida, pois colocam de lado a natureza complexa da imagem do

13 O que é o cinema? é uma compilação de textos editados em 4 volumes de 1958 a 1962 (ver Dudley Andrew, 1997). Neste texto, fazemos referência à data original de cada um dos textos, data essa retirada da edição $O$ que é $o$ Cinema? de 1992 dos Livros Horizonte (ver bibliografia).

${ }^{14} \mathrm{O}$ artigo "Contributos para uma ontologia do cinema" tem como base o texto escrito pelo mesmo autor e que se destinou a arguir as provas de Agregação de João Mário Grilo. Essas provas tiveram lugar na Universidade Nova de Lisboa a 30 de Setembro de 2002. A citação aqui apresentada foi retirada desse texto inicial. 
cinema. Essa natureza complexa é que poderá servir de suporte efectivo para uma teoria ontológica.

Mas, tudo isto não põe em causa o interesse nos pensamentos de Bazin e Kracauer. O que aqui iremos fazer é enquadrar esses autores naquilo que julgamos ser um enquadramento adequado; não estando em causa 0

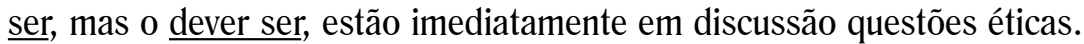

“O que devo fazer?", questão fundamental da Ética e que "está fora do âmbito daquelas a que as ciências positivas, inclusivamente as sociais e humanas, podem responder" (José Manuel Santos) diz respeito a normas a seguir. E, as teorias realistas tratam, no nosso entender, disso mesmo.

Um conceito que importa introduzir é o de deontologia, muito usado na discussão ética. Deontologia "qualifica uma ética centrada nos conceitos de dever e de norma. (Deontologia vem do particípio grego déon, que significa dever)." (ibid.). As éticas deontológicas estabelecem e fundamentam "uma obrigação moral e a respectiva norma”. Mas, o termo deontologia, para além de se referir aos sistemas éticos que "procuram fundamentar as normas do dever moral", tem um outro uso mais corrente; "o termo refere-se aos procedimentos considerados jurídica e moralmente bons numa dada área profissional." Assim, podemos falar de uma deontologia para determinadas actividades profissionais, por exemplo, medicina ou jornalismo que, em geral, incluem não apenas normas éticas mas, também, obrigações jurídicas e mesmo questões de tacto - "uma esfera de convenções culturais cuja essência axiológica está mais próxima do estético, das questões de bom gosto, do que do ético, mesmo se na maioria dos casos concretos, que a casuística das deontologias profissionais deve resolver, o ético e o estético se interpenetram." (ibid.) Logo, podemos considerar a hipótese de "código deontológico" próprio para o filme documentário. Mas, sobre esta questão concordamos com Brian Winston (2000) que considera os códigos da medicina e do jornalismo não aplicáveis ao filme documentário. Este pauta-se por um ponto de vista criativo e autoral que é contrário a essas actividades.

Se todas as éticas são normativas podem dividir-se em ética normativa de cariz deontológico (as acções são avaliadas "em função de normas que estipulam deveres ou obrigações"(ibid.), o mesmo é 
dizer, agir 'por dever') ou uma ética normativa de cariz teleológico (“os actos são avaliados em função das suas consequências, e não de normas deontológicas estabelecidas a priori."(ibid.), o mesmo é dizer, agir para atingir determinado fim considerado bom, i.e. um "bem supremo"). As éticas teleológicas são consequencialistas (determinada acção implica uma determinada consequência), mas podem haver "éticas consequencialistas que não sejam, no sentido estrito do termo, teleológicas" pois "não definem positivamente um 'bem supremo', não sendo por isso teleológicas no sentido estrito, mas que avaliam as acções na perspectiva das consequências que estas possam vir a ter, a mais ou menos longo prazo, para um summum malum, que deve ser evitado a todo o custo." (ibid.).

Entendemos que a teoria realista de Bazin é sustentada por uma ética consequencialista embora impere o cariz deontológico e que a teoria realista de Kracauer pressupõe uma ética de cariz teleológico.

Para Bazin o realismo do cinema reside em respeitar a unidade espacial de um acontecimento. A sua proposta é então clarificada no texto "Montagem interdita": "parece-me que se poderia pôr em lei estética o seguinte princípio: 'Quando o essencial de um acontecimento está dependente da presença simultânea de dois ou vários factores da acção, a montagem é interdita.' " (Bazin, 1957:67). No texto "A evolução da linguagem cinematográfica", Bazin reafirma os limites do realizador: "Decerto como o encenador de teatro, o realizador de cinema dispõe de uma margem de interpretação onde inflectir o sentido da acção. Mas é apenas uma margem que não deve modificar a lógica formal do acontecimento." (Bazin, 1955:81).

Se Bazin é categórico na "lei" que cria é-o menos quanto à sua aplicação. "É sem dúvida mais difícil definir a priori os géneros de assunto ou mesmo as circunstâncias a que se aplica esta lei. Só prudentemente me arriscarei a dar algumas indicações”. (Bazin, 1957: 69) Em primeiro lugar, a lei é naturalmente verdadeira para os documentários que têm como objectivo relatar factos. Por seu lado, nos documentários "exclusivamente didácticos, cuja finalidade não é a representação, mas a explicação do acontecimento" impõe-se o uso da planificação (que analisa o acontecimento, e onde o campo/contracampo é, em geral, utilizado). Mas, "muito mais interessante" 
é o filme de ficção "indo da magia, como Crina Branca, ao documentário um pouco romanceado como O Esquimó” [Nanuk, o Esquimó (1922) de Robert Flaherty]; "as ficções só adquirem sentido ou só têm valor pela realidade integrada no imaginário." (ibid.:70) e, finalmente, "no filme de narrativa pura, equivalente ao romance ou à peça de teatro". Bazin assegura que o sucesso do burlesco (Buster Keaton e Chaplin) advém dos gags mostrarem a unidade espacial, "da relação do homem com os objectos e o mundo exterior."

Mas, não se trata apenas de um ganho ou progresso na linguagem cinematográfica, Bazin diz que se afecta a relação do espectador com a imagem. Essa relação torna-se mais próxima, o que implica uma atitude mental mais activa por parte do espectador e, sobretudo, a montagem ao dar lugar à profundidade de campo permite "tudo exprimir sem dividir 0 mundo, de revelar o sentido oculto dos seres e das coisas sem lhes quebrar a unidade natural." (Bazin, 1955:88).

São bem conhecidos os elogios aos filmes que usam o plano-sequência em profundidade de campo (a luta com a foca no filme Nanook que mantém a unidade espacial e temporal do acontecimento, por exemplo), isto porque, antes de mais, Bazin defende que os filmes devem colocar em primeiro lugar a realidade do acontecimento e evitar a representação imaginária que o uso da montagem favorece. "basta, para que a narrativa reencontre a realidade que um só dos seus planos convenientemente escolhido reúna os elementos antes dispersos pela montagem.” (Bazin, 1957:69).

A aplicação da "lei" de Bazin evita aquilo que o próprio entenderia como um summum malum, ou seja, evita a representação imaginária e favorece a vocação realista do cinema. O maior inimigo para o cinema que Bazin defende é a montagem. No seu texto "A montagem interdita" (título bastante radical) pode ler-se: "A montagem só pode ser utilizada em limites precisos, sob pena de intentar contra a própria ontologia da fábula cinematográfica. Por exemplo, não é permitido ao realizador escamotear pelo campo e contracampo a dificuldade de dar a ver dois aspectos simultâneos de uma acção." (ibid.:64/6). O realizador deve agir por dever, as suas escolhas cinematográfica devem estar de acordo com a "lei" que Bazin justifique como o garante de um efectivo cinema realista. 
Se Bazin defende um realismo espacial em Kracauer está em discussão um realismo dos temas. Para Kracauer, mais sistemático que Bazin, o cinema possui propriedades básicas e propriedades técnicas. As primeiras são idênticas às propriedades da fotografia (com acrescento do movimento), ou seja, os filmes só possuem validade estética se registarem e revelarem a realidade física. "they must record and reveal physical reality" (Kracauer, 1960:37-nosso sublinhado). Daqui decorrem afinidades naturais do cinema com o mundo natural, a saber: o não-encenado, o fortuito, o infinito, o indeterminado e o "fluir da vida". Por seu lado, as propriedades técnicas que são específicas do meio, por exemplo, montagem, efeitos especiais, ... devem estar ao serviço das primeiras, devem favorecer e enaltecer as propriedades básicas, ou seja, a natural inclinação de registar o mundo físico. Kracauer parte do pressuposto que cada meio tem uma natureza específica e que essa sua natureza (propriedade básica) deve determinar o uso desse meio. No caso do cinema, essas propriedades básicas tornam o cinema o meio ideal para trazer de volta a nossa ligação com o mundo físico, ligação essa que tinha sido posta em causa com as ideologias e que a crescente importância da ciência não é capaz de nos dar, uma vez que é demasiado abstracta, afasta-nos da fisicalidade das coisas.

Um filme terá tanto mais valor quanto mais se fundamentar nas propriedades básicas do cinema. Os melhores filmes são os que sabem "recriar o sentido das coisas tal como elas são, na sua indeterminação e na sua ambiguidade." (Casetti, 1994:50 - nossa tradução). Os filmes que Kracauer defende como cinematográficos são os filmes de "história encontrada" ${ }^{15}$, filmes cujo argumento depende da realidade, do mundo, da própria vida, como é o caso dos filmes do neo-realismo italiano.

A propósito do fotógrafo afirma Kracauer: "In an aesthetic interest, that is, he must follow the realistic tendency under all circumstances" $(\mathrm{Kr}$ acauer, 1960:3-nosso sublinhado). Por seu lado, o realizador que apenas

${ }^{15}$ No original "found story". Theory of Film foi originalmente escrito em inglês, 1960. Na tradução para alemão a primeira edição data de 1964. A edição que consultámos, com ajuda de um tradutor, data de 1993, Ed. Die Deutsche Bibliothek, sendo traduzida por Friedrich Walter e Ruth Zellschan e revista pelo autor. Kracauer manteve o termo "story": "found story" foi traduzido para "Die gefundene Story”. 
tenha em conta as suas próprias motivações (sonhos, preocupações, obsessões) afasta-se da tendência realista e natural do cinema. Mas, em vez de ser apenas realista (de que Lumière é referência) ou formalista (de que Méliès é referência), o realizador deve encontrar um justo equilíbrio entre a tendência realista e a tendência mais criativa e esse equilíbrio só se alcança quando a segunda tendência não se sobrepõe à primeira, o mesmo é dizer, quando segue a tendência realista. Kracauer não apresenta nenhuma predilecção por determinadas técnicas (como Bazin pelo plano-seqüência), em vez disso interessa-lhe que as técnicas sejam usadas tendo em conta determinado fim. $\mathrm{O}$ cinema coloca o Homem na sua verdadeira relação com o mundo, assim abre-se caminho para uma ideologia comum baseada nessa relação próxima com a corporalidade das coisas. A união dos povos tornase então possível, mas apenas se fizer um uso judicioso do meio cinema. Apesar de não apresentar claramente normas a seguir, enveredando mais pelo que o realizador não deve fazer (deixar-se levar pelas seus próprios interesses) a teoria realista de Kracauer pressupõe claramente numa ética teleológica.

O que aqui propomos (ainda que arriscando demasiado) é que o Realismo é uma questão dependente da disciplina de Ética (cujo objectivo será então tematizar as normas morais das imagens cinematográficas) e os pensamentos de Bazin e Kracauer induzem-nos a pensar que o projecto de realismo que o filme documentário encerra, pode ser formulado do seguinte modo: a principal questão que se coloca ao documentário não é a realidade da representação, mas a ética da representação.

Poderá objectar-se da relação entre ética e estética, pois esta última ocupa lugar de destaque nas teorias realistas. Do ponto de vista estético as teorias realistas são propostas que preconizam o uso de determinados recursos em detrimento de outros e, no caso de Bazin, chega mesmo a ser uma proposta bastante clara e radical. Como já mencionámos acima (através de citação) ética e estética interpenetram-se. Finalizaremos referindo duas situações que evidenciam o modo como entendemos essa ligação - para nós, a ética encontra o seu suporte na estética. Numa primeira situação daremos destaque ao registo "nú e cru", depurado de preocupações estéticas a favor da espectacularidade, na outra está em 
causa uma exacerbada preocupação estética. Quanto à primeira, tomamos como referência a discussão de Marcius Freire (2004) a respeito das relações entre os filmes antropológicos e os chamados "shockumentary", filmes que exploram o exótico e o bizarro e que têm a sua origem nos inícios do cinema. Estes "shockumentary" têm na série Mondo Cane a sua pedra de toque. "Mondo Cane é construído na forma de um longo relato de viagem em que os costumes mais bizarros, mais distantes dos padrões ocidentais são mostrados sem qualquer pudor”, afirma Freire. Quanto aos primeiros, os filmes antropológicos, o autor toma como referência os filmes The Hunters (1958) de John Marshall e Dead Birds (1963) de Robert Gardner. A propósito do filme The Hunters, Marcius Freire refere: “o abate da girafa no final do filme não deixa de lembrar algumas cenas de Mondo Cane"; por seu lado, no filme Dead Birds, após uma batalha entre tribos, "grandes planos exploram os ferimentos, a retirada das pontas de lança dos corpos, o arfar dos feridos." The Hunters e Dead Birds são exemplos de filmes antropológicos que possuem um estatuto mais elevado que os da série Mondo Cane, uma vez que estão embasados de um "valor científico". Marcius Freire questiona esse estatuto e entende que "a fronteira que os separa do seus congêneres menos credenciados academicamente é bastante tênue." Ou seja, o enquadramento científico deixa de ter qualquer relevância face a uma equivalência estética por demais evidente.Qualquer conclusão do ponto de vista ético terá em conta a estética (ou falta dela).

Quanto ao caso de uma excessiva preocupação estética, leia-se o texto de Serge Daney, "O travelling de Kapo". A propósito do filme sobre os campos de concentração, Kapo (1960) de Gillo Pontecorvo, escreve Daney: "É que eu nunca vi Kapo mas, ao mesmo tempo, vi-o. Vi-o porque alguém - através das palavras - mo mostrou. Este filme, cujo título, como uma senha, acompanhou toda a minha vida de cinema, só o conheço através de um curto texto: a crítica que fez Jacques Rivette em Junho de 1961 nos Cahiers du Cinéma. Era o número 120, o artigo chamava-se 'Da abjecção', Rivette tinha trinta anos e eu dezassete. Acho que até aí nunca tinha sequer pronunciado a palavra 'abjecção' em toda a minha vida. No seu artigo, Rivette não contava o filme; contentava-se, numa frase, em descrever um plano. Essa frase gravou-se-me na memória e dizia o seguinte: 'Vejam em 
Kapo, o plano em que Riva se suicida, atirando-se sobre o arame farpado electrificado: o homem que decide fazer, nesse momento, um travelling para reenquadrar o cadáver em contra-picado, tendo o cuidado de colocar a mão erguida num ângulo preciso do seu enquadramento final, este homem só tem direito ao mais profundo dos desprezos. Assim um simples movimento de câmara podia também ser o movimento que não se devia fazer. Aquele que deveria - de modo evidente - ser abjecto fazer. Mal tinha lido estas linhas, soube que o seu autor tinha absolutamente razão. Abrupto e luminoso, o texto de Rivette permitia-me descrever esse rosto da abjecção. (...) Com alguém que não sentisse imediatamente a abjecção do 'travelling de Kapo', eu não teria, definitivamente, nada a ver, nada a partilhar. (...) Qualquer pessoa podia agora perceber que existissem - mesmo, e sobretudo, no cinema - tabus, facilidades criminosas e montagens interditas. A fórmula célebre de Goddard, que via nos travellings 'uma questão de moral', era, para mim, um desses truísmos sobre os quais não se podia ceder." (Daney, 1992:206) E, mais adiante: "Psico, La Dolce Vita, O Túmulo Índio, Rio Bravo, Pickpocket, Anatomia de um crime, O Herói sacrílegio ou, justamente, Nuit et Brouillard não são para mim filmes como os outros. À questão brutal "isto olha-te?", respondem-me todos que sim. Os corpos de Nuit et Brouillard e, dois anos depois, os corpos dos primeiros planos de Hiroshima mon amour são coisas que me olham mais do que eu as olhei a elas.” (Daney, 1992:208). Se como diz, Daney Noite e Nevoeiro não é um filme belo, mas um filme justo - era Kapo quem queria ser um filme belo - um cineasta tem responsabilidades para com os espectadores e para com quem filma, é necessário que fique claro, para os espectadores que têm de "compreender ao mesmo tempo que os campos de concentração eram verdadeiros e que o filme era justo.” (Daney, 1992:207).

Mais importante que tudo o mais - parafraseando Serge Daney - o cinema ensina-nos a perceber pelo olhar, a que distância de cada um de nós está o Outro.

Ainda sobre Kapo, explica Daney: "O travelling era imoral pela boa razão que nos colocava, a ele cineasta e a mim espectador, onde não estávamos. Lá, onde eu, em qualquer dos casos, não podia estar nem queria estar. Porque ele me 'deportava' da minha situação real de espectador- 
testemunha para me incluir à força no seu enquadramento. Ora, que sentido poderia ter a fórmula de Godard senão que nunca nos devemos colocar onde não estamos, nem falar no lugar dos outros." (Daney, 1992:220).

Daney encontrou no "clip de televisão": "We are the children, We are the world", uma actualização do filme Каро. O clip "entrelaçava, langorosamente, imagens de cantores completamente famosos e de crianças africanas completamente famintas. (...) Fundindo e encadeando estrelas e esqueletos num pestanejar figurativo no qual duas imagens se tentavam fazer numa só (...) Eis, dizia-me, o rosto actual da abjecção do meu "travelling de Kapo". Gostaria que enojassem um adolescente de hoje; ou pelo menos que o fizessem envergonhar. Que não só o envergonhassem de se saber bem alimentado e cuidado, mas que o envergonhassem de ser considerado como alguém que podia ser esteticamente seduzido por aquilo." (Daney, 1992:220).

Ainda que o cinema seja capaz (em muitos filmes) de redimir a televisão, será sempre urgente proceder a uma constante desactualização do "travelling de Kapo".

\section{REFERÊNCIAS}

ANDREW, J. Dudley. "Concepts in Film Theory". Oxford, New York, Toronto, Melbourne: Oxford University Press, 1984.

. “André Bazin's ‘Evolution’”. In LEHMAN, Peter (ed.). “Defining Cinema: The Athlone Press", 1997. pp.73-94.

ARAUJO, Denize Correa. “Linhas de fuga' na cinematografia brasileira contemporânea”. In CCCC-Ciências da Comunicação em Congresso na Covilhã, III SOPCOM, VI LUSOCOM, II IBÉRICO, UBI-Universidade da Beira Interior, Abril 2004 (no prelo para o livro de Actas do Congresso, data prevista de edição: Fevereiro 2005).

BAZIN, André. Ontologia da imagem fotográfica. In BAZIN, André. o que é o Cinema? Lisboa: Col. Horizonte de cinema, Livros Horizonte, 1992. pp. 13-21. 
. “O mito do cinema total", ibid., pp.23-29.

A evolução da linguagem cinematográfica, ibid., pp. 71-89 (Nota: este ensaio é uma síntese de 3 artigos, optamos por usar a data do último desses artigos. Cf. Livro O que é o Cinema? atrás mencionado).

Montagem interdita, ibid.,pp.57-70 (Nota: este ensaio tem a indicação "in Cahiers do Cinéma, 1953 e 1957", optamos por usar a última data).

CARROLL, Noël. "From real to reel: entangled in non-fiction film" in CARROLL, Noël. "Theorizing the Moving Image”. Cambridge University Press, 1996. pp. 224-252.

. "Kacauer's theory of film". In LEHMAN, Peter (ed.). "Defining Cinema", London, The Athlone Press, 1997. pp.111-131.

CASETTI, Francesco. "Teorías del Cine”. Madrid: Cátedra, 1994.

DANEY, Serge (1992), “O 'travelling' de Kapo”. In Revista de Comunicação e Linguagens, $\mathrm{n}^{0} 23$, O que é o Cinema?, Org. GRILO, João Mário; MONTEIRO, Paulo Filipe. Lisboa: Ed. Cosmos, 1996. pp. 205-221. (Original: "Le travelling de Kapo" in revista Trafic, Outono 1992 e posteriormente in Persévérance, Entretien avec Serge Toubiana, Paris, P.O.L., 1994).

FIDALGO, António (no prelo). "Contributos para uma Ontologia do Cinema”, Universidade da Beira Interior.

FREIRE, Marcius. "Fronteiras imprecisas: o documentário antropológico entre a exploração do exótico e a representação do outro” in CCCCCiências da Comunicação em Congresso na Covilhã, III SOPCOM, VI LUSOCOM, II IBÉRICO, UBI-Universidade da Beira Interior, Abril 2004 (no prelo para o livro de Actas do Congresso, data prevista de edição: Fevereiro 2005).

GRILO, João Mário. A Ordem no Cinema, Vozes e Palavras de Ordem no Estabelecimento do Cinema em Hollywood. Lisboa: Col. Grande Plano, Relógio d’Água Editores, 1997. 
. Relatório da Disciplina Teórico-Prática de Filmologia, Universidade Nova de Lisboa [não publicado], 2000

KRACAUER, Siegfried. "Theory of Film, The Redemption of Physical Reality”. Princeton, New Jersey: Princeton University Press, 1960.

NICHOLS, Bill. "Introduction to Documentary". Bloomington \& Indianapolis, Indiana University Press, 2001.

SANTOS, José Manuel (s/ data). Ética da Comunicação in BOCCBiblioteca on-line de Ciências da Comunicação www.bocc.ubi.pt [Manual da disciplina de Ética].

WISEMAN, Frederick. Um Olhar sobre as Instituições Americanas. Catálogo da Cinemateca Portuguesa, 1994. 